\title{
Treatment of involuntary movement disorders with tetrabenazine
}

\author{
MICHAEL SWASH, A. H. ROBERTS, HAZIM ZAKKO, \\ AND K. W. G. HEATHFIELD \\ From the Neurological Department, Section of Neurological Sciences, \\ The London Hospital, London, and Claybury Hospital, Woodford, Essex
}

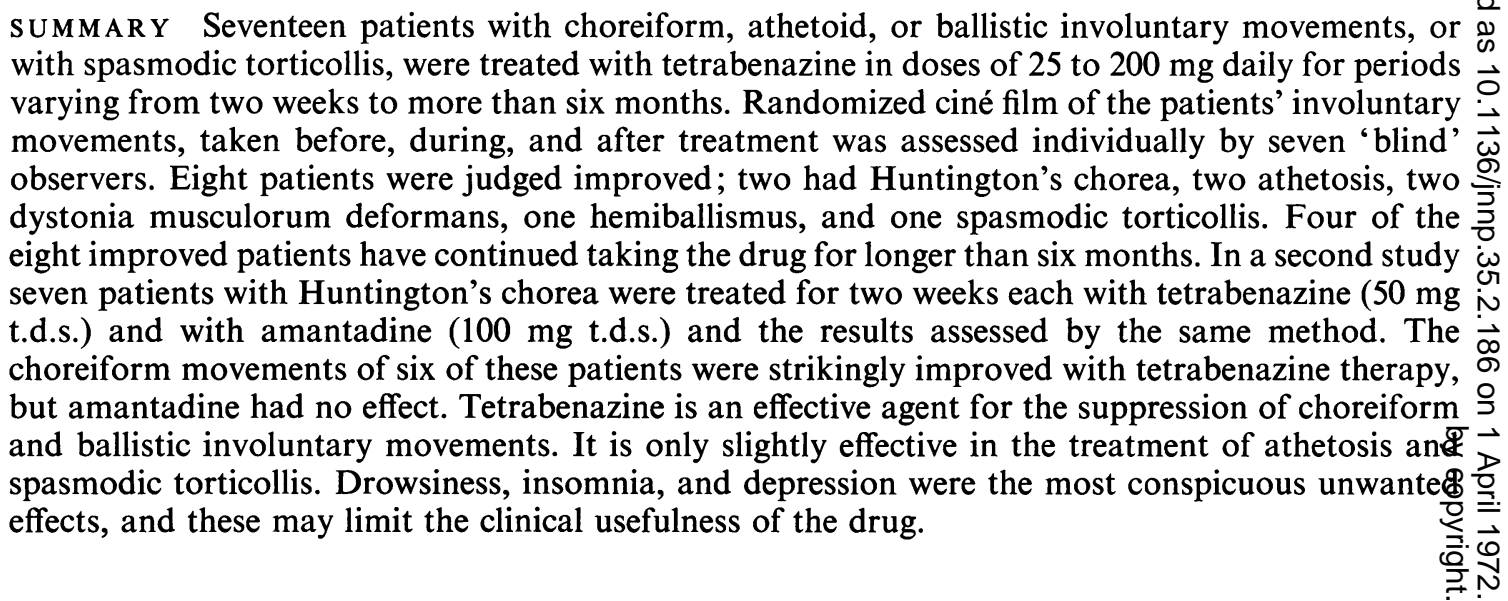

Tetrabenazine (Nitoman, Roche) is a synthetic benzoquinolizine which, like reserpine, causes depletion of dopamine and other monoamines in the central nervous system. It lacks the peripheral effects of reserpine and so is less likely to cause postural hypotension. Tetrabenazine was first introduced as an antipsychotic agent but it was soon superseded by the phenothiazines and was then withdrawn from the British market, although it remained available elsewhere. Reserpine itself produces Parkinsonism as a dosedependent side-effect and Forrest (1957) showed that it could be used to suppress the involuntary movements of Huntington's chorea without producing coincidental Parkinsonism, although at the cost of intolerable depression, drowsiness, hypotension, and weight gain. The similarity of the central actions of reserpine and tetrabenazine then led to trial of tetrabenazine in various involuntary movement disorders, and brief reports of its effectiveness, especially in Huntington's chorea, appeared in the continental literature (Brandrup, 1960; Pakkenberg, 1968). These reports escaped attention in Great Britain but interest in the drug was awakened by Dalby's
(1969) report of uncontrolled observations of the effectiveness of tetrabenazine in the treatment of various involuntary movements. He found that the drug was useful only in the treatment of chorea and hemiballismus. We have studied the effects of the drug in these and other movement disorders and report the results in this paper.

\section{EFFECTIVENESS OF TETRABENAZINE METHODS}

We first studied the effects of tetrabenazine in 17 patients suffering from athetoid, choreiform, or ballistic involuntary movements or from spasmodic torticollis. These patients agreed to try the drug after the methods and aims of the trial had been explained to them. They were selected because they had very severe and intractable involuntary movements and were otherwise in good health.

Because we intended to study the relation between dose and degree of suppression of involuntary movements, tetrabenazine was prescribed individually, స్ట the dose varying according to therapeutic result and $\sigma$ tolerance to unwanted effects. Fourteen patients were treated as outpatients, attending at weekly intervals, and three as inpatients. The drug was $\stackrel{\mathcal{Q}}{\rightarrow}$ begun at a dose of $25 \mathrm{mg}$ twice daily and increased 
by $25 \mathrm{mg}$ increments at three day intervals. Since tolerance to tetrabenazine varied considerably, reliance was placed on the patients, who were all highly motivated to cooperate within the study, to inform us of the dose level achieved at each visit, and this was checked by counting their returned tablets. At the weekly visits each patient's involuntary movements were assessed clinically and any untoward effects of treatment were noted.

Assessment of the severity of involuntary movements is, inevitably, a highly subjective task and when assessments are made at intervals during a period of several weeks observer variation becomes increasingly likely, even if a scoring system is used. The use of randomized film overcomes this difficulty and enables individual assessment to be made by a large number of suitably skilled observers all of whom can easily be kept unaware of the methodological details of the trial design. In addition, all the observations can be made on a single occasion and the film is available for future study if required. We have found this method easy to use and it has obvious application to the assessment of the efficacy of treatment in other neurological disorders.

At each visit a short $16 \mathrm{~mm}$ colour film was made of the patients' involuntary movements, both at rest, during walking, and during the performance of a simple task of manual dexterity-usually filling a small box with pins. The purpose of the film was explained and a dummy run was made in each case before the first control film was taken, and care was taken to repeat the filmed sequences as exactly as possible at each visit so that they could be compared easily. At the end of the trial, three uncut film sequences were selected from the available film of each patient so that in each case there remained one sequence made before treatment had begun, one made during treatment with the highest tolerated dose of tetrabenazine, and one made a week after treatment had been stopped. The three film sequences of each patient were randomized according to an incomplete Latin square design and the 17 sets of three sequences were joined to make a 45 minute film which was shown to an audience of neurologists and neurosurgeons at The London Hospital, none of whom had been concerned with the trial in any way and all of whom had had more than five years' clinical neurological experience. These 'blind' observers were asked to note on a form which of the three film sequences of each patient showed the least severe and which showed the most severe involuntary movements. Collaboration between observers was not allowed. There were, therefore, 34 choice situations and in each of these any one of the seven observers could choose only one of three possible alternatives. Agreement of six of the seven 'blind' observers was required before an assessment was accepted as meaningful, since with this criterion agreement of all seven of the observers was highly unlikely to have occurred by chance $(P=0.01)$.

TABLE 1

CLINICAL DETAILS IN 17 PATIENTS

\begin{tabular}{|c|c|c|c|c|c|c|c|c|c|}
\hline Diagnosis & Case & Sex & $\begin{array}{l}\text { Age } \\
(y r .)\end{array}$ & $\begin{array}{l}\text { Clinical } \\
\text { response }\end{array}$ & $\begin{array}{c}\text { Film } \\
\text { analysis }\end{array}$ & $\begin{array}{c}\text { Worse } \\
\text { when TBZ } \\
\text { stopped }\end{array}$ & $\begin{array}{c}\text { Duration } \\
\text { of therapy } \\
\text { (weeks) }\end{array}$ & $\begin{array}{c}\text { Maximum } \\
\text { dose } \\
(m g / d a y)\end{array}$ & $\begin{array}{c}\text { Effective } \\
\text { dose } \\
(m g / \text { day })\end{array}$ \\
\hline Perinatal hypoxia & 1 & $\mathbf{M}$ & 25 & + & + & + & 3 & 125 & 100 \\
\hline \multirow[t]{2}{*}{ Bilateral athetosis } & $2(\mathrm{~S})$ & M & 44 & 0 & 0 & 0 & 4 & 125 & - \\
\hline & 3 & $\mathbf{M}$ & 20 & + & + & + & $30+$ & 150 & 100 \\
\hline \multirow{5}{*}{$\begin{array}{l}\text { Dystonia musculorum } \\
\text { deformans }\end{array}$} & $4(S)$ & $\mathbf{M}$ & 21 & + & + & + & 4 & 100 & 75 \\
\hline & 5 & $\mathbf{M}$ & 17 & + & 0 & + & 4 & 150 & - \\
\hline & 6 & $\mathbf{M}$ & 29 & + & + & 0 & 5 & 175 & 150 \\
\hline & 7 & $\mathbf{M}$ & 30 & 0 & 0 & 0 & 2 & 100 & - \\
\hline & 8 & $F$ & 8 & 0 & 0 & 0 & 3 & 75 & - \\
\hline \multirow[t]{3}{*}{ Spasmodic torticollis } & 9 & $\mathbf{M}$ & 52 & 0 & 0 & 0 & 4 & 200 & - \\
\hline & 10 & $F$ & 41 & + & 0 & + & 4 & 75 & - \\
\hline & 11 & $\mathrm{~F}$ & 70 & + & + & + & 4 & 75 & 50 \\
\hline \multirow[t]{2}{*}{ Huntington's chorea } & 12 & $\mathbf{M}$ & 44 & + & + & + & $30+$ & 150 & 50 \\
\hline & 13 & $\mathbf{M}$ & 67 & + & + & + & $30+$ & 150 & 100 \\
\hline Hemiballismus & 14 & $F$ & 67 & + & + & + & $30+$ & 75 & 25 \\
\hline $\begin{array}{l}\text { Progressive athetoid } \\
\text { dystonia }\end{array}$ & 15 & $\mathbf{M}$ & 40 & + & 0 & + & 8 & 200 & -- \\
\hline $\begin{array}{l}\text { Hypoxic encephalopathy! } \\
\text { athetosis }\end{array}$ & $16(S)$ & $\mathrm{F}$ & 51 & 0 & 0 & 0 & 3 & 150 & - \\
\hline Kernicterus/athetosis & 17 & $\mathbf{M}$ & 25 & + & 0 & + & 3 & 75 & - \\
\hline
\end{tabular}

$\mathrm{TBZ}=$ tetrabenazine

(S) = stereotactic thalamotomy.
Mean age of all patients $48 \mathrm{yr}$, range 8 to 70 . (Seventeen patients.) Mean age of improved patients $48 \mathrm{yr}$, range 20 to 70 . (Eight patients.) Effective dose range 25 to $150 \mathrm{mg}$ daily $=$ mean, $80 \mathrm{mg}$ daily. 


\section{RESULTS}

Using these criteria, there was agreement in eight of the 17 'least severe' choice situations (see Table 1). The eight 'least severe' sequences were all filmed during the period of therapy and it therefore seemed likely that these assessments represented a response to therapy. In the 'most severe' choice situation there were seven agreed assessments. Five of these were filmed before treatment had been begun, one after treatment had been stopped, and one actually during treatment (case 7). In those choice situations in which agreement of six of the seven 'blind' observers was not reached, there were never more than three rankings for any one of the three alternative choices, so that separation of the agreed and statistically highly significant results from those not agreed was very clear cut.

The eight patients judged improved by the 'blind' observers had all been assessed improved on clinical grounds during the course of the trial, but there were four other patients, also thought to be improved on clinical grounds, who were not judged improved by the 'blind' observers. These four patients had themselves decided not to continue tetrabenazine at the end of the trial, although they seemed to deteriorate when the drug was withdrawn. Their improvement was probably not significant.

Four of the eight patients who were objectively improved have continued tetrabenazine for longer than six months. One of these patients (case 14) became depressed while taking $75 \mathrm{mg}$ daily, but her mood quickly returned to normal when the drug was stopped. However, her hemiballismus then reappeared and was so disabling that she has since restarted tetrabenazine and, while taking $25 \mathrm{mg}$ daily, has achieved satisfactory control of her involuntary movements, without depression. If she omits this small dose involuntary movements return and intensify during the following eight to 36 hours. Case 3 , suffering from bilateral athetosis due to perinatal hypoxic encephalopathy is partially, but usefully, improved with $100 \mathrm{mg}$ tetrabenazine daily, and at this dose, is free from unwanted effects. Two patients with Huntington's chorea (cases 12 and 13) are strikingly improved on $50 \mathrm{mg}$ and $100 \mathrm{mg}$ daily respectively and, although case 12 noticed some drowsiness, this is acceptable in view of the degree of improvement achieved. In both cases the drug has had no effect on the mental changes due to the disease. The remaining four patients judged improved by the 'blind' observers have not continued the drugs for longer than the trial period either because the response was unsustained in spite of maintained or increased dosage (cases 1, 6, and 11), or because of intolerable drowsiness (case 4). One patient with dystonia musculorum deformans (case 7) was made worse by treatment with tetrabenazine, but quickly recovered when treatment was stopped.

Thus two of the three patients with athetosis secondary to perinatal hypoxia were improved and one of these has continued the drug; two of the five patients with dystonia musculorum deformans were improved but neither of these has continued the drug; one of the three patients with spasmodic torticollis was improved, but did not continue the drug; both the patients with Huntington's chorea were improved, and both have continued treatment and the only patient with hemiballismus was improved and has continued treatment. All the patients improved by tetrabenazine experienced return of their involuntary movements within 48 hours of stopping the drug. There was no relation betweer improvement and previous stereotactic thalaê motomy.

The mean age of the eight improved patient was the same as that of the whole group (48 years, range 20 to 70 years). The effective dose achieved varied from 75 to $200 \mathrm{mg}$ daily. Thirteen of the 17 patients continued treatment for two to eight weeks (mean four weeks) and the remaining four patients have continued the drug for longer than six months. Two patients continued guanethidine, methyldopa, and chlorothiazide and two other patients continued benzhexol during the trial. No interaction between these drugs and tetrabenazine was noticed.

UNWANTED EFFECTS Drowsiness was a dosedependent effect, although individual susceptibility differed and all patients complained of some drowsiness at their maximum dosage. Insomnia occurred at lower dosage and seemed to give way to drowsiness as the dose was increased. Depression, which occurred in two patients, was also a dose-dependent effect and like drowsiness seemed to appear at a higher dose than that which satisfactorily suppressed involuntary movements, when the drug did so. We did not observe hypotension in our patients. Other unwanted effects are summarized in Table 2. 
TABLE 2

UNWANTED EFFECTS (17 PATIENTS)

\begin{tabular}{ll}
\hline Severe drowsiness & 4 \\
Insomnia & 3 \\
Depression & 2 \\
Feelings of unreality & 1 \\
Myoclonus & 1 \\
\hline
\end{tabular}

\section{TETRABENAZINE AND AMANTADINE IN HUNTINGTON'S CHOREA}

A second study was undertaken to assess the effectiveness of tetrabenazine in the treatment of the involuntary movements of Huntington's chorea by comparing its effects with those of amantadine (Symmetrel, Geigy). Amantadine was chosen for comparison because it was thought that this drug might increase the severity of the involuntary movements of Huntington's chorea and thus act as an active control substance for the 'blind' assessments. L-Dopa has been shown to have such an effect (Klawans, Paulson, and Barbeau, 1970), and amantadine is an effective anti-Parkinsonism substance with few side-effects (Schwab, England, Poskanzer, and Young, 1969).

\section{METHODS}

Seven patients with long-standing Huntington's chorea were selected from a group of such patients in long-term care at Claybury Hospital. The criteria for selection were that the patients should have obvious involuntary movements, should be able to stand and walk at least a few steps unaided, and should otherwise be in good health. All were suffering from dementia of varying degree. Their ages ranged from 38 to 82 years (mean 61 years). Several were taking phenothiazines or sedatives. These and all other drugs were stopped two weeks before the trial began. The patients and nurses knew only that they were taking part in a trial of the effects of two new drugs in Huntington's chorea, and it was hoped that the difference between the two drugs would be emphasized by their different size, shape, and colour. Each patient was treated for two weeks with tetrabenazine $(50 \mathrm{mg}$ t.d.s.) and for two weeks with amantadine $(100 \mathrm{mg}$ t.d.s.). In each case the dose was increased gradually to these levels during the first five days of treatment. Three patients received tetrabenazine first and four amantadine first, and each patient had a week off treatment between the two courses of drugs. The study was organized at Claybury Hospital and the patients were examined there daily by H.Z. All patients were examined at a visit to the London Hospital (M.S.) before the trial began, on the last day of tetrabenazine therapy and on the last day of amantadine therapy, and on each of these occasions a ciné film was made of their involuntary movements. The film sequences were then randomized and assessed by the same group of 'blind' observers, using the methods described above.

\section{RESULTS}

Six of the seven patients were judged improved during the period of tetrabenazine treatment by the 'blind' observers, the 'blind' clinical assessor (M.S.), and by the day to day assessor (H.Z.) (Table 3). In five of these patients the

TABLE 3

SEVEN PATIENTS WITH HUNTINGTON'S CHOREA: RESPONSE TO TETRABENAZINE

\begin{tabular}{lcccc}
\hline Sex & $\begin{array}{c}\text { Age } \\
(y r .)\end{array}$ & $\begin{array}{c}\text { Duration of } \\
\text { illness } \\
(y r .)\end{array}$ & $\begin{array}{c}\text { Objective } \\
\text { clinical } \\
\text { response }\end{array}$ & $\begin{array}{c}\text { Film } \\
\text { analysis }\end{array}$ \\
\hline F & 67 & $>10$ & + & + \\
F & 68 & $>10$ & + & + \\
F & 82 & $>50$ & 0 & 0 \\
F & 46 & 5 & + & + \\
F & 55 & 6 & + & + \\
M & 38 & 12 & + & + \\
M & 59 & 12 & + & + \\
\hline
\end{tabular}

involuntary movements were almost completely suppressed. The one patient who was not improved became confused with tetrabenazine and assessment was then very difficult. Three patients became drowsy and two appeared more confused than usual during treatment with tetrabenazine. All these effects were reversed when the drug was stopped. There was no relation between improvement and age or duration of disease.

In the dose prescribed, amantadine had no effect either on the involuntary movements or on the mental state of these patients. No unwanted effects were observed during its use.

\section{DISCUSSION}

Our results confirm the striking suppressive effect of tetrabenazine on the involuntary movements of Huntington's chorea reported by Brandrup (1960), Sattes (1960), and Dalby (1969). Hemiballismus was alleviated similarly. Some of our patients with athetosis due to perinatal hypoxia or to dystonia musculorum deformans, and one of our patients with spasmodic torticollis, were also objectively improved. Apart from the patients reported here, we have also treated one patient with senile chorea, one with 
chorea gravidarum, and one with recurrent Sydenham's chorea and have observed almost complete suppression of the involuntary movements in each case (uncontrolled observations). In our experience the involuntary movements of chorea, of any cause, are quickly and sometimes almost completely suppressed, but athetoid movements improve very little. Brandrup (1961) and MacCallum (1970) have reported that the persistent dyskinesias of phenothiazine medication can also be relieved by tetrabenazine.

Reserpine produces Parkinsonism as a dosedependent effect in normal subjects but neither we nor others have observed this effect during the treatment of involuntary movements with tetrabenazine. However, Parkinsonism was a common unwanted effect when tetrabenazine was used in a dose of 75 to $150 \mathrm{mg}$ daily as an antipsychotic agent (Ashcroft, MacDougall, and Barker, 1961; Pletscher, Brossi, and Gey, 1962) and the reason for its absence in patients given tetrabenazine for the treatment of involuntary movements is not known. In animal studies both reserpine and tetrabenazine have been shown to deplete striatal dopamine and 5-hydroxytryptamine, but tetrabenazine prevents reserpineinduced depletion of brain 5-hydroxytryptamine and also prevents reserpine-induced drowsiness, probably because it occupies the same cerebral receptor sites. In addition, animals treated with tetrabenazine show reduced motor activity (Pletscher et al., 1962). This evidence suggests that dose-dependent Parkinsonism and dosedependent suppression of involuntary movements with tetrabenazine therapy in man are the result of depletion of striatal dopamine, and perhaps other cerebral monoamines. This hypothesis is supported by the occurrence of dose-dependent choreiform and athetoid involuntary movements in patients with Parkinsonism during treatment with L-dopa, and is in accordance with the theory of a physiological equilibrium between the opposing actions of cholinergic and dopaminergic neuronal systems in the basal ganglia (see Calne and Sandler, 1970). This theory suggests that increased activity of the cholinergic system, or reduced activity of the dopaminergic system exacerbates hypokinesia, tremor, and rigidity of Parkinsonism and the converse activity in these systems improves Parkinsonism and releases certain involuntary movements. So far, however, there is no biochemical evidence of abnormal cerebral dopamine or other monoamine metabolism in choreic, athetoid, or ballis- tic states and the application of this theory to these disorders therefore remains speculative. In this context, it is of interest that tetrabenazine had more suppressive effect on choreiform than on athetoid movements, and one patient with dystonia musculorum deformans was actually made worse by the drug. Amantadine, unlike L-dopa, did not modify the involuntary movements of Huntington's chorea in any of the seven patients treated with the drug. This may be further evidence that its mode of action is different from that of L-dopa.

Depression occurred in two of our first 17 patients $(12 \%)$. This incidence is comparable with the 7.5 to $30 \%$ recorded in trials of reserpine therapy in hypertension (Tricou, 1964). This is a potentially serious side-effect and several instances of attempted suicide, apparently due to tetrabenazine-induced depression, were recorded in the earlier trials of the drug in psychiatric practice. Monoamine oxidase inhibitors, by counteracting the monoamine depleting action of tetrabenazine in the central nervous system, can be used to counteract this induced depression, although, since the striatal dopamine conten will then increase, it might be expected tha involuntary movements would reappear.

Although drowsiness occurred in all ouE patients at their maximum dosage, it did so at the effective dose range in only two of the eight patients improved by tetrabenazine in the first group of 17 patients. Tolerance developed in three of these eight improved patients and this effect limited the usefulness of the drug, although it was only observed in patients with athetosis.

We wish to thank Dr. R. A. Henson and Dr. C. J. Earl for allowing us to study patients under their care at The London Hospital, and Dr. J. S. Pippard and Dr. F. D. Kelsey for permission to study patients under their care at Claybury Hospital. Roche Products, Ltd. and Geigy Pharmaceuticals, Ltd. kindly supplied us with tetrabenazine and amantadine and defrayed the cost of film used in the trial. We would also like to thank Mr. R. Ruddick for undertaking all the photographic work.

\section{REFERENCES}

Ashcroft, G. W., MacDougall, E. J., and Barker, P. A. (1961). A comparison of tetrabenazine and chlorpromazine in chronic schizophrenia. Journal of Mental Science, 107, 287293.

Brandrup, E. (1960). Reserpin og tetrabenacin ved chorea Huntington. Nordiske Medecin, 64, 968-969. 
Brandrup, E. (1961). Tetrabenazine treatment in persisting dyskinesia caused by psychopharmaca. American Journal of Psychiatry, 118, 551-552.

Calne, D. B., and Sandler, M. (1970). L-Dopa and Parkinsonism. Nature (London), 226, 21-24.

Dalby, M. A. (1969). Effect of tetrabenazine in extrapyramidal movement disorders. British Medical Journal, 2, 422-423.

Forrest, A. D. (1957). Some observations on Huntington's chorea. Journal of Mental Science, 103, 507-513.

Klawans, H. C., Paulson, G. W., and Barbeau, A. (1970). Predictive test for Huntington's chorea. Lancet, 2, 11851186.

MacCallum, W. A. G. (1970). Letter to Editor. British Medical Journal, 1, 760.

Pakkenberg, H. (1968). The effect of tetrabenazine in some hyperkinetic syndromes. Acta Neurologica Scandinavica, 44, 391-393.

Pletscher, A., Brossi, A., and Gey, K. F. (1962). Benzoquinolizine derivatives-a new class of monoamine decreasing drugs with psychotropic action, in International Review of Neurobiology, Vol. 4, pp. 275-303. Edited by C. C. Pfeiffer and J. R. Smythies. Academic Press: New York.

Sattes, H. (1960). Die Behandlung der chorea major mit dem Manoamin-Freisetzer Nitaman. Psychiatria Neurologia Neurochirurgia, 140, 13-19.

Schwab, R. S., England, A. C., Poskanzer, D. C., and Young, R. R. (1969). Amantadine in the treatment of Parkinson's disease. Journal of the American Medical Association, 208, $1168-1170$

Tricou, B. J. (1964). Reserpine and depression. Journal of the American Medical Association, 188, 943. 